\title{
REINVENTANDO SÍSIFO: REFLEXÕES SOBRE A LEGITIMAÇÃO DA ÉTICA NA PRÁTICA DE PESQUISAS EDUCACIONAIS
}

\author{
PATRÍCIA CLAUDIA COSTA
}

Universidade Federal de Viçosa

RESUMO Este ensaio visa colocar em discussão alguns limites éticos enfrentados pela autora, em experiências de pesquisa, no campo educacional. Toma como base de reflexão seus trabalhos ao longo da formação em Mestrado e Doutorado, grande parte pautada por metodologia autobiográfica, bem como orientações de pesquisas que tem realizado, as quais utilizam questionários e entrevistas para coletar dados em universos que variam com relação à idade, nivel de formação e localização geográfica dos sujeitos. Problematiza, especialmente, as exigências para a obtenção de Parecer emitido por Comitês de Ética em Pesquisa com Seres Humanos e, por fim, destaca a urgência de uma avaliação sensata, com vistas à reestruturação dos atuais critérios para a aprovação de projetos de pesquisa na área de Humanidades, especialmente dos procedimentos para cadastro na Plataforma Brasil, tendo em vista a aprovação dos projetos pelo Sistema CEP/CONEP.

Palavras-chave: Metodologia de pesquisa. Pesquisa qualitativa. Abordagem (auto)biográfica

\section{ABSTRACT REINVENTING SÍSIFO: REFLECTIONS ABOUT LEGITIMACY OF ETHICS IN THE PRACTICE OF EDUCATIONAL RESEARCHES}

This essay aims to discuss some questions concerning the legitimacy of ethics in the practice of educational researches. It is based on the author's own experience during her master and PhD graduate courses, mostly guided by (auto)biographical methodology, and also on her current practice of research, based on questionnaires and interviews, in order to collect data in different types of universes, which vary with respect to age, education level and geographical localization of the researched subjects. Emphasis the urgency of a reasonable evaluation, with a view to a reestructuration of the current criteria for the approval of research projects in the area of Humanities, 
specially the registration procedures on Plataforma Brasil to approve the projects through Sistema CEP/CONEP.

Keywords: Research methodology. Qualitative research. (Auto)biographical approach.

\section{RESUMEN REINVENTANDO SÍSIFO: REFLEXIONES SOBRE LA LEGITIMACIÓN DE LA ÉTICA EN LA PRÁCTICA DE INVESTIGACIONES EDUCATIVAS}

Este ensayo objetiva discutir algunos límites éticos enfrentados por la autora en experiencias de investigaciones en el ámbito de la educación. Se basa en la reflexión sobre su labor a lo largo de la formación en el Máster y en el Doctorado, asentados sobretodo, en el método autobiográfico, así como en investigaciones que ha realizado y dirigido, las cuales utilizan cuestionarios y entrevistas para la toma de datos en universos que varían con respecto a la edad, nivel de formación educacional y localización geográfica de los sujetos. Pone de manifesto la urgencia de una evaluación sensata, con vista a la reestructuración de los criterios actuales para la aprobación de los proyectos de investigación en el área de las Ciencias Humanas, especialmente de los procedimientos para registro de proyectos en la Plataforma Brasil objetivando la aprobación por el Sistema CEP/ CONEP.

Palabras clave: Metodología de investigación. Investigación cualitativa. Enfoque (auto)biográfico.

\section{Introdução}

No intuito de contribuir para uma reflexão que favoreça a invenção de formas mais sensatas de validar eticamente as pesquisas feitas na área de Humanidades (aqui entendida como o conjunto das Ciências Humanas e Sociais), este ensaio funda-se numa analogia que explicita como os procedimentos atualmente exigidos para a aprovação de projetos correspondem a esforços inúteis que sobrecarregam o conjunto de tarefas que docentes e discentes universitários assumem cotidianamente. Trata-se da expressão popular "Trabalho de Sísifo", originada na mitologia grega, que designa todo tipo de trabalho ou situação repetitiva, inútil ou interminável.
Diz a lenda que Sísifo era um mortal muito esperto, que conseguia ludibriar até os deuses, obtendo deles proveitos para si próprio e para a sua comunidade. Até que um dia, Zeus decidiu pôr um fim em suas astúcias e condenou - o a empurrar uma pedra enorme para o topo de uma montanha. E assim ele ficou por toda a eternidade, tentando colocar a pedra no lugar determinado, porque ela rolava para baixo toda vez que ele estava chegando ao cume. Com tal lenda em mente, este ensaio pretende explicitar que o que tem acontecido no meio acadêmico brasileiro, no que diz respeito à legitimação da ética em pesquisas com seres humanos, tem muitas semelhanças com o mito de Sísifo. Para 
tanto, estrutura-se nas seguintes seções: (1) apresentação da gênese da preocupação com esse fenômeno, situada na prática de pesquisa da autora; (2) discussão dos entraves impostos pela necessidade de obtenção de um Parecer de Ética para validar a execução de projetos e a publicação dos resultados de pesquisa; e (3) reflexões a respeito dos obstáculos enfrentados em pesquisas no campo educacional.

\section{As pesquisas}

As reflexões expostas neste ensaio foram suscitadas por alguns constrangimentos enfrentados ao empreender pesquisas com seres humanos, especialmente pela experiência de pesquisa que se iniciou em 2006, sem nenhuma pretensão de se tornar um estudo longitudinal, e foi retomada em 2018, com o intuito de verificar a situação atual de letramento de mulheres idosas. Àquela época, ambicionavase apenas produzir uma dissertação de Mestrado em Educação, que tratasse da motivação de pessoas idosas para frequentar um núcleo de alfabetização, situado na periferia de Guarulhos/SP (COSTA, 2008). Logo de início, a opção pela metodologia (auto)biográfica, especificamente na perspectiva de autobiografia educativa, mostrou-se a mais adequada ao propósito de estender o alcance do trabalho para além dos objetivos acadêmicos, utilizando-o como instrumento de formação do público que contribuiu para a sua realização.

O processo de coleta de dados durou quase um ano e foi, de fato, formativo, por incluir práticas de alfabetização e letramento. Confirmou-se, assim, a tese de Josso (2004), de que a importância da metodologia de pesquisa e de formação autobiográfica reside, fundamentalmente, na característica de constituir-se como um meio de proporcionar aos sujeitos a oportunidade de vivenciar, simultaneamente, o papel de sujeito e de objeto de sua formação.
Após publicar a dissertação e alguns artigos dela decorrentes, dirigi meus interesses de pesquisa para outro tema, mas sempre adotando a perspectiva (auto)biográfica. Durante o doutorado, investiguei trajetórias de docentes universitários de origem popular (COSTA, 2017), ou seja, trabalhei com uma amostra de entrevistados, situados em vários municípios paulistas, cujas trajetórias de formação eram muito distintas daquelas que eu havia aprendido a analisar até então. Nessa investigação, o caráter formativo era mais sutil, nem sempre se revelava e não era intencional (COSTA, 2016). Concluído aquele trabalho, dei-me conta de que a dissertação estava prestes a completar dez anos de publicação e lembrar dela aguçou minha curiosidade epistemológica (FREIRE, 2010), a ponto de projetar um prolongamento do estudo sobre a situação atual de letramento do grupo outrora investigado.

À primeira vista, revitalizar uma pesquisa que abordou sujeitos idosos, conferindo a ela uma perspectiva longitudinal, pode parecer um tanto arriscado ou até descabido. Não havia nenhuma garantia de que os sete sujeitos seriam reencontrados, muito menos de que ainda estivessem todos vivos. Contudo, a convicção de que tal empreitada poderia esclarecer aspectos não alcançados naquela dissertação (que passou a ser considerada como "primeira etapa do estudo") justificou o esforço de buscar novas narrativas que serviriam não só para aprofundar a análise sobre os processos formativos, no âmbito da educação popular, como para refletir sobre questões teórico-metodológicas que pude amadurecer ao longo da última década. Então, estabeleci como objeto do novo projeto a situação de letramento de ex-educandas do MOVA-Guarulhos, durante o período de 2008-2017, considerando-o como a segunda etapa de um estudo longitudinal, que passaria a se desenvolver em etapas quinquenais enquanto houvesse remanescentes. $\mathrm{A}$ hi- 
pótese principal, que foi parcialmente confirmada, era a de que não houve continuidade da escolarização e que a situação de letramento atual seria mais precária do que a verificada em 2008. Para verificá-la, propus realizar uma entrevista individual e testes de leitura e escrita junto a cada sujeito.

A discussão proposta não incide sobre os resultados de ambas as etapas desse estudo, cuja análise encontra-se no prelo, mas sobre alguns problemas éticos enfrentados nessa experiência, regida pelo Parecer CEP-UFV no 2.652.801 e cadastrada na Plataforma Brasil sob no 88048318.7.0000.5153. A exposição feita até aqui tem a finalidade de situar os problemas expostos na próxima seção, os quais também têm sido encontrados em pesquisas em nível de Trabalho de Conclusão de Curso (TCC) e de Iniciação Científica (IC) - cujos sujeitos são estudantes, adolescentes e jovens de municípios da Região Metropolitana de Belo Horizonte/MG - que compõem o projeto "Relações entre desigualdades sociais e desigualdades escolares", aprovado conforme Parecer CEP-UFV 3.077.865 e cadastrado na Plataforma Brasil sob no 01435718.4 .0000 .5153 .

\section{Os entraves em nome da ética}

A garantia da ética no processo de coleta e publicação de dados de pesquisa em Humanidades padece de extravagantes exigências impostas pelos Comitês de Ética em Pesquisa (CEP). ${ }^{1}$ A extravagância ${ }^{2}$ começa pelo fato de

1 Vinculados a instituições que realizam pesquisas, constituem-se como colegiados independentes de natureza técnico-científica multidisciplinar e de caráter consultivo, deliberativo e educativo. Integram o Sistema CEP/ CONEP. Essa segunda sigla significa Comissão Nacional de Ética em Pesquisa e funciona como parte integrante do Conselho Nacional de Saúde (CNS), criada através da Resolução 196/96 e com constituição designada pela Resolução 246/97, com a função de implementar as normas e diretrizes regulamentadoras de pesquisas envolvendo seres humanos, aprovadas pelo Conselho.

2 Seguindo a definição dada pelo Dicionário Houaiss de Língua Portuguesa, ao usar a palavra "extravagância" este texto se refere à "ação que escapa às normas ge- que todo CEP opera de acordo com princípios da área de Saúde, independentemente da área de conhecimento na qual o projeto em análise se enquadra. Isso se deve ao fato de que as Resoluções que determinam as diretrizes e normas regulamentadoras de pesquisas envolvendo seres humanos são formuladas pelo Ministério da Saúde. E mesmo quando se tentou adequar a Resolução 466/2012/CNS (BRASIL, 2012), ainda em vigor, aproximando-a de procedimentos mais pertinentes às metodologias e possibilidades de trabalho no campo das Humanidades, a formulação dos procedimentos obrigatórios ainda segue a lógica do Código de Nuremberg, criado em 1947. A Resolução 510/2016/CNS (BRASIL, 2016) avançou em alguns aspectos, mas manteve algumas extravagâncias que serão discutidas mais adiante.

É importante ressaltar que os motivos que levaram à elaboração do Código de Nuremberg originaram-se dos abusos cometidos em experimentos da área médica durante a Segunda Guerra Mundial. Criado, portanto, num tempo em que pesquisadores foram levados a um tribunal e julgados por crimes, contra a humanidade e de guerra, caracterizados pela realização irresponsável de experimentos com seres humanos, sem preocupação com os riscos e causando sérios danos físicos, psicológicos e morais, inclusive mutilações e mortes. Surge daí o que tem sido chamado de "ética nuremberguiana", a qual se resume como aquela "que se fundamenta no consentimento livre e esclarecido; no cálculo dos riscos e beneficios para o sujeito da pesquisa; na qualificação científica do condutor da pesquisa; e na distinção entre pesquisa clínica terapêutica e não terapêutica" (ALBUQUERQUE, 2013, p. 413).

Essa ética permanece intacta até no léxico utilizado nas Resoluções do CNS (BRASIL, 1996; 1997; 2012; 2016) e, consequentemente, nos do-

rais do bom senso [...]; esquisito". (HOUAISS; VILLAR, 2009, p. 863) 
cumentos que os pesquisadores brasileiros precisam produzir para validar suas pesquisas. Não há dúvidas de que sua necessidade é tão atual hoje como em 1947, pois a ânsia de realizar uma grande descoberta científica, conjugada à falta de escrúpulo de certos ramos que fomentam as pesquisas, pode resultar em danos tão graves quanto os praticados pelos criminosos julgados em Nuremberg. E mesmo que a situação não chegue a esse extremo, só o fato de que alguns procedimentos podem lesar a integridade e a dignidade do ser humano já seria suficiente para justificar a necessidade de uma rigorosa regulação da prática científica.

Acontece que toda a lógica presente desde o Código de Nuremberg até a Resolução 510/2016/CNS (BRASIL, 2016) está impregnada pelas possibilidades de ação em pesquisas na área da Saúde. Na tentativa de demonstrar como essa lógica é extravagante para pesquisas em Ciências Sociais e Humanas, destacarei alguns detalhes que fazem do cumprimento das exigências dos CEPs um exercício tolo que traz alguns embaraços às pesquisas.

Esses detalhes giram em torno de duas exigências: a apresentação de todos os instrumentos de coleta, os quais não poderão ser alterados no decorrer da execução do projeto, e o registro do consentimento. Mas antes de tratar das exigências, vale trazer para a discussão um problema igualmente delicado: a obsessão por formalidades nutrida por alguns membros da comunidade acadêmica.

\section{Se não está na Plataforma Brasil, a pesquisa não existe}

A Plataforma Brasil entrou em funcionamento no ano de 2012, com ampla divulgação e utilização entre pesquisadores da área da Saúde. Até os dias de hoje, continua estruturada para cadastro de projetos na área da Saúde, embora ofereça opção para registro de pesquisas em outras áreas de conhecimento, já que todos os projetos submetidos ao Sistema CEP/CONEP dão entrada por lá. Tal estrutura tem sido constante alvo de críticas, o que resultou na Carta Circular no. 110-SEI/2017-CONEP/SECNS/MS (BRASIL, 2017), publicada em 08 de dezembro de 2017, elaborada pela Instância CHS/CONEP, em 26/10/2017 (leia-se CHS como Ciências Humanas e Sociais), que teve "por objetivo orientar pesquisadores e membros do sistema CEP/ CONEP quanto ao preenchimento da Plataforma Brasil no tocante as pesquisas que utilizam metodologias próprias das áreas de Ciências Humanas e Sociais, na versão atual da PB". A Carta orienta os pesquisadores a preencherem diversos itens obrigatórios do formulário com a expressão "Não se aplica" ou “inserir o número 0 ". Isso demonstra a inadequação do modelo de registro dos projetos aos padrões de construção das pesquisas em Humanidades.

Quando iniciei o Doutorado, em 2013, a cultura de registrar os projetos na Plataforma Brasil ainda não havia se instalado na área da Educação, tanto por ser algo recente, como por sua vinculação ao Ministério da Saúde. Usualmente, as pesquisas em Humanidades eram avaliadas por Comissões ou Comitês de Ética das instituições onde ocorria a formação do pesquisador. Por se tratar de um projeto que coletaria dados (por meio de questionários on - line e entrevistas) de docentes universitários, tive o cuidado de submetê-lo à aprovação da Comissão de Ética da Faculdade de Educação da Universidade de São Paulo (FEUSP) ${ }^{3}$ e da Reitoria da Universidade Federal de São Paulo (Unifesp), que apresentou a proposta da pesquisa aos pró-reitores e obteve anuência unânime para que se realizasse nessa instituição.

Munida de ambas as aprovações, iniciei a coleta com o envio de um questionário on-line para os e-mails ${ }^{4}$ de todos os professores efe-

3 Tendo obtido o Parecer FEUSP 49/2014.

4 Os endereços foram fornecidos pela universidade, 
tivos. Apesar de lograr $24 \%$ de respostas válidas, o que pode ser considerado exitoso nesse tipo de abordagem, alguns docentes manifestaram estranhamento e resistência, apontando suspeitas quanto à ética dos procedimentos. Isso se manifestou de várias maneiras. A mais frequente incidiu sobre a ausência de Termo de Consentimento no formulário. Algumas pessoas nos responderam questionando francamente a conduta e justificando que não participariam da coleta em função dessa ausência, mesmo com nosso esclarecimento de que o termo individual se fazia desnecessário porque obtivemos previamente autorização formal da instituição para a coleta de dados em massa. Ao que me parecia na época, esse era o procedimento padrão e apenas segui uma orientação comum da área. Entretanto, outros dois sujeitos nos cobraram o registro da pesquisa na Plataforma Brasil e esforçamonos para esclarecer que nossa instituição ainda seguia o antigo procedimento de aprovar os projetos por seus próprios Comitês, em processos que ainda seguiam a forma impressa e eram arquivados ao invés de publicados, como naquela plataforma. Houve, ainda, um sujeito que inquiriu o orientador sobre a veracidade da pesquisa, motivado pela observação de que a mesma não figurava entre a lista de orientações cadastradas em seu currículo Lattes. Vale destacar que todas essas manifestações foram feitas por docentes que atuavam na área da Saúde, ou seja, por agentes sociais habituados a cumprir os protocolos nuremberguianos. A desconsideração das pesquisas não cadastradas na Plataforma Brasil pauta-se na convicção de que o registro do projeto "protege" os sujeitos:

A principal missão do Sistema CEP/CONEP é garantir a proteção dos sujeitos de pesquisa. Não

juntamente com outros dados cadastrais, mediante assinatura de um termo de confidencialidade que assegurava o uso dos dados para fins exclusivos da pesquisa. há como proteger alguém retrospectivamente! Proteção se faz para o futuro, e não para o passado... Neste sentido, se o pesquisador realizar procedimentos com os sujeitos de pesquisa antes de obter a aprovação do Sistema CEP/ CONEP, seja o mero recrutamento, tais procedimentos já não poderão ser respaldados pela análise ética. ${ }^{5}$

As pequenas mazelas supracitadas ilustram como as pesquisas podem ser dificultadas, em nome de uma busca artificial de respaldo ético. E estando entre colegas de profissão, cabe indagar o que justificaria a pulsão de desmerecimento de um trabalho científico que sequer representa concorrência. Por que alguém se recusa a colaborar com pesquisas desenvolvidas em área de conhecimento alheia, desconsiderando as especificidades das áreas e reivindicando que todos conduzam os trabalhos como costuma conduzir os seus? A resposta mais plausivel parece ser a que sugere uma espécie de obsessão por formalidades, inculcada por um sistema de valores que motiva os pesquisadores a estimar mais o processo do que os resultados, mais o cumprimento de protocolos do que o uso responsável dos dados obtidos. E assim seguimos empurrando a pesada pedra... Desperdiçando tempo e energia, por exemplo, ao enviar questionários a sujeitos que se recusam a respondê-los em nome da convicção de que "sua pesquisa não existe, procurei na Plataforma Brasil e não localizei nada com seu nome". ${ }^{6}$

\section{Construir instrumento de coleta faz parte da formação do pesquisador?}

É muito comum encontrarmos em manuais de metodologia científica a definição das etapas

5 Disponivel em: <https://cep.prpi.ufg.br/p/10879-oque-deve-ser-analisado-pelo-sistema-cep-conep>. Acesso em: 30 set. 2018 (Grifo do autor).

6 Mensagem pessoal, recebida pelo e-mail <pesquisaunifesp@gmail.com>, em 13 ago. 2014. 
de construção de um projeto de pesquisa, entre as quais a elaboração dos instrumentos de coleta que, por um ordenamento lógico próprio da racionalidade científica, só poderia acontecer após o estudo do referencial teórico-metodológico que norteia a investigação. Dito de outro modo, uma das partes obrigatórias de todo projeto é seu cronograma de execução, onde se registra a previsão de quando e como os dados serão coletados e analisados. No entanto, os instrumentos que serão usados na coleta devem ser construídos ao longo da execução do projeto, pois a construção dos mesmos faz parte da prática científica em si. Inclusive nos niveis iniciais, como os Trabalhos de Conclusão de Curso e os de Iniciação Científica, é muito importante que os estudantes enfrentem o desafio de formular as questões apropriadas para atingir os objetivos e testar as hipóteses de suas pesquisas, sejam aquelas componentes de questionário, formulário, entrevistas ou roteiros de observação. A formulação dos instrumentos faz parte, portanto, do processo de "colocar a pesquisa em andamento":

Por mais parcial e parcelar que seja um objeto de pesquisa, só pode ser definido e construído em função de uma problemática teórica que permita submeter a uma interrogação sistemática os aspectos da realidade colocados em relação entre si pela questão que lhes é formulada. (BOURDIEU; CHAMBOREDON; PASSERON, 2004 , p. 48 , grifo dos autores)

Por mais que o autor do projeto já tenha algum acúmulo acerca da "problemática teórica" que sustenta a pesquisa, a formulação do conteúdo da "interrogação sistemática" não pode ser levada a cabo antes de uma incursão teórica orientada por um pesquisador experiente e isso só se efetiva ao longo da execução, ou seja, não é possivel submeter um projeto para aprovação, antes de iniciar seu cronograma, com questionários e roteiros de entrevista já prontos. A prática de definir os instrumentos no momento de redigir o projeto e elaborar as questões que os compõem, posteriormente, não é exclusividade das Humanidades. Ao contrário, ao buscar na base Scielo os descritores "metodologia científica" e "instrumento de coleta", surpreendeu-me encontrar uma grande variedade de trabalhos na área da Saúde, especialmente na Enfermagem, que explicitam a (re)construção dos instrumentos ao longo da pesquisa, como se pode observar neste excerto:

Relato de experiência que visa demonstrar a importância da participação de acadêmicos de enfermagem na elaboração um instrumento de coleta de dados para avaliação das famílias com idosos. Para construção do instrumento, os discentes entraram em contato com o referencial teórico do estudo. Logo após elaborou-se o instrumento, realizando em seguida o teste piloto permitindo encontrar falhas relativas à clareza e objetividade das questões. Posteriormente readaptou-se e aplicou-se nas famílias com idosos. (MOTA et al, 2011 p. 389)

Em Humanidades, procedemos de modo semelhante. Sendo comum utilizar "questionário-piloto" ou "entrevista-piloto" para "calibrar" as perguntas que devem ser feitas aos sujeitos. Isso é o que deveria continuar acontecendo na prática, porém o cumprimento das exigências para cadastrar os projetos na Plataforma Brasil inclui a obrigatoriedade de apresentar os instrumentos de coleta prontos para aplicação. E essa submissão deve ser feita em tempo hábil para que o projeto seja aprovado antes do início da coleta, pois não será admitido nenhum dado coletado e nenhum Termo de Assentimento ou Consentimento assinado em data anterior à data de aprovação do projeto pelo Sistema CEP/CONEP. Isso quer dizer que o projeto deve ser submetido alguns meses antes da data prevista para início da coleta, para que não se corra o risco de ter que adiar as atividades previstas no cronograma original, 
em virtude da espera pela emissão do Parecer de Ética, que nem sempre acontece na primeira apreciação. Em projetos de pesquisa em nível de Graduação, cujo prazo de execução não costuma exceder o período de 12 meses, esse fluxo de trabalho constitui um grande entrave.

No entanto, os editais relacionados aos programas de Iniciação Científica costumam destacar a importância de despertar bolsistas e voluntários(as) para a "vocação científica", por meio do aprendizado dos modos de produção científica. Por exemplo, entre os objetivos do Programa Institucional de Bolsas de Iniciação Científica fomentado pelo Conselho Nacional de Desenvolvimento Científico e Tecnológico (CNPq), lê-se o seguinte:

- proporcionar ao bolsista, orientado por pesquisador qualificado, a aprendizagem de técnicas e métodos de pesquisa, bem como estimular o desenvolvimento do pensar cientificamente e da criatividade, decorrentes das condições criadas pelo confronto direto com os problemas de pesquisa.

Diante desse objetivo, indago: como "estimular o desenvolvimento do pensar cientificamente e da criatividade" e, ao mesmo tempo, ensinar "métodos e técnicas de pesquisa" a estudantes que são obrigados a cumprir protocolos que receberam prontos, pois os prazos e exigências para a aprovação dos projetos pelo Sistema CEP/CONEP não permitem que eles participem efetivamente da elaboração dos instrumentos de coleta? Será mesmo preciso comprometer a formação científica na área de Humanidades, cujos métodos e técnicas praticamente não acarretam riscos e danos aos sujeitos que colaboram nas pesquisas, em nome de uma ética nuremberguiana, que se justifica pelo combate de abusos que muito excepcionalmente poderiam sobrevir em nossos trabalhos?

7 Informação on-line disponivel em: <http:/ / www.cnpq. br/web/guest/pibic>. Acesso em: 26 set. 2018.
Até mesmo pesquisadores da área da Saúde já reconheceram a complexidade dessa questão, tal como vemos no ensaio escrito por uma ex-coordenadora de CEP, que defende que as normas do Sistema CEP-CONEP, “apesar de serem necessárias, não são capazes de abarcar a complexidade das questões que se apresentam; sendo indispensável e urgente o exercício de uma cultura ética" (AMORIM, 2017, $\mathrm{s} / \mathrm{p})$. Para a autora, "mais do que impor regras aos atores envolvidos na questão, precisa-se estimular o desenvolvimento de uma competência moral, para que possam realizar julgamentos e agirem em conformidade com eles" (AMORIM, 2017, s/p). Diz ainda que:

[...] uma pesquisa social na área das humanidades, não poderá ser avaliada sob os mesmos parâmetros utilizados na análise de um ensaio clínico, e vice-versa; ou ainda, mesmo se tratando de dois ensaios clínicos, cada um terá peculiaridades éticas que deverão ser avaliadas, com base nas suas características particulares. (AMORIM, 2017, s/p)

\section{Termos de Assentimento e}

\section{Consentimento: para que tanta formalidade?}

No que diz respeito aos Termos de Assentimento ou de Consentimento, ${ }^{8}$ cabe iniciar a problematização buscando por seu fundamento, qual seja, o de assegurar que o sujeito participe da pesquisa de forma livre e esclarecida. Por livre, entende-se que não sofreu nenhuma coação, nem foi vítima de falsas explicações ou promessas que o colocassem em uma situação em que não houvesse a opção consciente de participar da pesquisa. Por esclarecido, pressupõese que o sujeito recebeu todas as informações e dizimou todas as dúvidas necessárias como

8 Os Termos de Consentimento devem ser assinados por participantes com idade superior a 18 anos ou pelos responsáveis legais de participantes com idade inferior a 18 anos, que devem assinar o Termo de Assentimento. 
garantia de sua livre participação consciente. Assegurar esses dois direitos é essencial em qualquer pesquisa. 0 problema é que entre a garantia dos direitos e o registro do consentimento ou assentimento pode haver grandes diferenças.

Primeiramente, por mais que as Resoluções recomendem que os Termos de Consentimento (ou Assentimento) Livre e Esclarecido (TCLE) sejam redigidos em linguagem acessível ao participante, quem trabalha com certos segmentos sociais conhece bem a dificuldade que muitos sujeitos possuem para interpretar os textos mais simples. Afinal, até entre a população escolarizada o nível de compreensão de textos é, em diversas situações, aquém do necessário para assegurar o esclarecimento do conteúdo de um TCLE. De acordo com a última publicação do Indicador de Alfabetismo Funcional (INAF), ${ }^{9}$ apenas $12 \%$ dos respondentes são proficientes, $25 \%$ estão na condição intermediária, $34 \%$ enquadram-se no nível elementar e $30 \%$ compõem o contingente de sujeitos em nivel rudimentar ou analfabetos (LIMA; CATELLI JÚNIOR, 2018, p. 8). Quando os resultados são analisados com relação ao nível de escolaridade dos sujeitos participantes desse estudo, observa-se a presença de analfabetos funcionais até mesmo entre pessoas que concluíram a Educação Superior (4\%), o Ensino Médio (13\%) ou Fundamental (34\%). Esses percentuais sugerem que uma significativa parcela da população não teria plenas condições de compreender um TCLE sem intervenção do pesquisador. $E$ é isso que se verifica quando somos obrigados a coletar assinaturas de pessoas em situação precária de letramento ou de crianças e adolescentes.

9 Desde 2001, os níveis de alfabetismo da população brasileira têm sido medidos pelo INAF. Participam desse estudo pessoas entre 15 e 64 anos de idade, residentes em zonas urbanas e rurais de todas as regiões do país. $O$ intervalo de confiança estimado é de $95 \%$ e a margem de erro máxima estimada é de 2,2 pontos percentuais.
A obrigatoriedade do registro do consentimento gera mais constrangimentos do que garantia de direitos. Vamos por partes. A Resolução 510/2016/CNS (BRASIL, 2016) avançou no que diz respeito à forma de registrar o consentimento. Enquanto na Resolução 466/2012/CNS (BRASIL, 2012), a assinatura de um TCLE era a única forma de registro considerada, a Resolução posterior admite que o registro seja feito "sob a forma escrita, sonora, imagética, ou em outras formas que atendam às características da pesquisa e dos participantes" (BRASIL, 2016, Art. 15). Sem detalhar como essas formas poderiam ser executadas, a nova regulação permite maior flexibilidade para o cumprimento da obrigatoriedade do registro. No entanto, a cultura letrada está de tal modo impregnada no imaginário acadêmico que, quando se pensa em registrar o consentimento, logo este se associa à assinatura de um TCLE. E é aí que reside o maior problema. Por mais que simplifiquemos a linguagem, a quantidade de detalhes que devem constar no registro do consentimento é de uma abrangência que torna a leitura do documento um constrangimento para muitos participantes. Isso porque, de acordo com a Resolução 510/2016/CNS (BRASIL, 2016, p.), todo TCLE deve conter o seguinte:

Art. 17. O Registro de Consentimento Livre e Esclarecido, em seus diferentes formatos, deverá conter esclarecimentos suficientes sobre a pesquisa, incluindo:

I- a justificativa, os objetivos e os procedimentos que serão utilizados na pesquisa, com informação sobre métodos a serem utilizados, em linguagem clara e acessivel, aos participantes da pesquisa, respeitada a natureza da pesquisa;

II - a explicitação dos possíveis danos decorrentes da participação na pesquisa, além da apresentação das providências e cautelas a serem empregadas para evitar situações que possam causar dano, considerando as características do participante da pesquisa; 
III - a garantia de plena liberdade do participante da pesquisa para decidir sobre sua participação, podendo retirar seu consentimento, em qualquer fase da pesquisa, sem prejuízo algum;

IV - a garantia de manutenção do sigilo e da privacidade dos participantes da pesquisa seja pessoa ou grupo de pessoas, durante todas as fases da pesquisa, exceto quando houver sua manifestação explícita em sentido contrário, mesmo após o término da pesquisa;

V - informação sobre a forma de acompanhamento e a assistência a que terão direito os participantes da pesquisa, inclusive considerando beneficios, quando houver;

$\mathrm{VI}$ - garantia aos participantes do acesso aos resultados da pesquisa;

VII - explicitação da garantia ao participante de ressarcimento e a descrição das formas de cobertura das despesas realizadas pelo participante decorrentes da pesquisa, quando houver;

VIII - a informação do endereço, e-mail e contato telefônico, dos responsáveis pela pesquisa;

IX - breve explicação sobre o que é o CEP, bem como endereço, e-mail e contato telefônico do CEP local e, quando for o caso, da CONEP; e

$X$ - a informação de que o participante terá acesso ao registro do consentimento sempre que solicitado.

$\S 1$ o Nos casos em que algum dos itens não for contemplado na modalidade de registro escolhida, tal informação deverá ser entregue ao participante em documento complementar, de maneira a garantir que todos os itens supracitados sejam informados aos participantes.

§ 2 - Nos casos em que o consentimento ou o assentimento livre e esclarecido não for registrado por escrito, o participante poderá ter acesso ao registro do consentimento ou do assentimento sempre que solicitado.

$\S 3$ ㅇ Nos casos em que o consentimento ou o assentimento livre e esclarecido for registrado por escrito uma via, assinada pelo participante e pelo pesquisador responsável, deve ser entregue ao participante.
Exemplificando os constrangimentos com o caso da experiência longitudinal que deu origem a este ensaio, das quatro entrevistadas, apenas uma conseguiu ler o documento até o final e, antes de assinar, comentou: "Eu não entendi muita coisa, mas tudo bem. Onde é que assina?". Outras duas começaram a ler e, antes de chegar à metade do texto, pediram explicação sobre o que estava escrito ali. A última sequer tentou ler e assinou sem demonstrar interesse de ser esclarecida quanto aos detaIhes presentes no TCLE. Antes de solicitar a leitura e a assinatura, expliquei os propósitos da pesquisa e a metodologia empregada, na linguagem mais coloquial possivel. No entanto, quando as mesmas informações são transmitidas na forma escrita, os sujeitos demonstram suas dificuldades de leitura e tais situações foram até consideradas como parte da coleta, já que o principal objetivo da pesquisa era verificar a situação de letramento. 0 maior problema é que tal desconforto poderia ser evitado, caso os registros de consentimento fossem dispensados nas situações em que o pesquisador percebesse o cumprimento dessa parte do protocolo como um fator de inibição da coleta. Nas pesquisas da área da Educação, é muito comum o uso das técnicas de questionário e entrevista. Quais danos os procedimentos pertinentes a tais técnicas poderiam causar em pessoas em situação precária de letramento que fossem mais graves do que a vergonha de revelar a incapacidade de ler e compreender um documento? Essa pergunta não é retórica e não se aplica apenas a idosas egressas de um movimento de alfabetização. Ela aponta um problema real que também pode acontecer com menores de idade diante de um Termo de Assentimento Livre e Esclarecido, bem como com seus pais diante do TCLE, em exemplo que explicarei a seguir. Só quem já coletou assinatura de pessoas pouco capazes de compreender um texto escrito sabe como é angustiante 
cumprir essa parte do protocolo de pesquisa. Além de constranger o sujeito, este ato impinge uma espécie de artificialidade à relação pesquisador-pesquisado que passa a ser regida por uma formalidade que ambos reconhecem ser desnecessária, apesar de ser exigida pelo Sistema CEP/CONEP para assegurar a proteção e a autonomia:

Exalta-se muito o princípio da autonomia; porém, em algumas situações há de se questionar a respeito dessa autonomia e da dignidade do ser humano: Será que existe autonomia, onde faltam os meios para suprir as necessidades mais básicas do ser? Nesse panorama, também, surgem questões em torno do TCLE: Será que, em estado de vulnerabilidade socioeconômica e analfabetismo, não se teria, na maioria das vezes, no máximo, um termo de consentimento informado e assinado, ao invés de livre e esclarecido? Faltam estudos, pesquisa e monitoramento nesse sentido. (AMORIM, 2017, s/p)

O constrangimento não está apenas na demonstração da precariedade da leitura (em termos de fluência e compreensão), mas também na natureza das dúvidas que o documento suscita. Ao colocar em evidência a possibilidade de riscos e danos, esses termos assustam alguns sujeitos. Uma das entrevistadas perguntou-me, ao final do nosso encontro, cerca de duas horas depois de ter lido e assinado o TCLE: "é muito perigoso ajudar pesquisa?" Por não ter compreendido sua dúvida, indaguei por que estava perguntando isso e ela respondeu: "é que naquele documento que eu assinei dizia que você tem que me pagar uma indenização e eu não entendi como é que você pode me prejudicar". A pergunta fazia muito sentido. Se há previsão de indenização, pressupõe-se a possibilidade de que alguém seja lesado. $E$ como é que um pesquisador explica, a alguém que acabou de the conceder uma entrevista, que esse alerta é apenas uma formalidade, que na verdade não existe risco algum porque seguimos padrões éticos no tratamento dos dados e que essa garantia consta no TCLE só porque existe uma resolução do CNS que nos obriga a escrever o documento deste jeito para poder aprová-lo no Sistema CEP/CONEP? Escrevo assim sem vírgulas para mostrar como é de perder o fôlego. Essa situação, a meu ver, é o ápice da artificialidade do registro do consentimento, ${ }^{10}$ que pode se tornar mais agudo no caso do registro escrito.

Tais situações apontam para outra discussão relevante, cujo aprofundamento foge aos limites deste ensaio, qual seja a do poder que a prática científica, tal como empreendida nos moldes aqui apresentados, tem de excluir justamente grupos que já são excluídos: analfabetos ou pessoas em situação precária de letramento, independentemente da idade, do território, da ocupação etc. Contudo, há certamente um traço comum a esses grupos: o da pobreza. E assim, o silenciamento dos pobres e marginalizados, no contexto das pesquisas acadêmicas, impõe-se como efeito colateral, perverso e sutil, de uma prática pretensamente neutra e ética. ${ }^{11}$ Isso pode não se constituir um problema para outras áreas de conhecimento, mas em Humanidades, sobretudo em pesquisas conduzidas por metodologias (auto) biográficas, o fato de "dar voz aos excluídos" corresponde simultaneamente à finalidade e justificativa de diversos projetos, que se desenvolveriam com menor dificuldade se não

10 Certa vez, discutindo com estudantes de Graduação sobre os termos utilizados em TCLEs, um deles satirizou: "seria mais coerente colocar que os eventuais riscos de aplicação de questionário em turmas do Ensino Médio seriam o de algum respondente usar a folha sulfite para cortar o próprio pulso". Apesar da ironia, aí está um risco real que talvez não fosse bem acolhido pelos pareceristas do CEP responsáveis por apreciar o projeto. No entanto, a artificialidade gerada pelo empenho em adequar nossos protocolos aos consagrados modelos da área médica leva-nos a redigir TCLEs que despertam mais dúvidas do que esclarecimentos.

11 Para aprofundar a reflexão sobre a impossibilidade de qualquer ciência ser neutra, ler dois importantes textos de Pierre Bourdieu: "Un acte désintéressé est-il possible" (1994) e "Os usos sociais das ciências" (2004). 
fossem obrigados a trabalhar como Sísifo para cumprir todos os protocolos.

Com relação ao problema de coleta de assinaturas junto aos pais de crianças e adolescentes, a insistência em seguir modelos de procedimento da área da Saúde também afeta negativamente o trabalho em pesquisas educacionais. Em uma pesquisa clínica, por exemplo, é importantíssimo que os pais estejam cientes dos procedimentos aos quais seus filhos serão submetidos, principalmente quando invasivos ou propensos a oferecer riscos reais aos participantes. Dependendo do local de realização dos procedimentos e do tipo de pesquisa desenvolvida, é muito comum que os pais acompanhem as situações de coleta de modo que o contato entre eles e a equipe de pesquisa torna possivel que todos os esclarecimentos sejam feitos para que a assinatura do TCLE seja realmente livre e esclarecida. Já no campo educacional, esse contato raramente é possivel. 0 mais comum é que pesquisadores coletem dados e percam parcelas importantes por não obter as assinaturas necessárias. De acordo com as Resoluções do CNS, somente os dados respaldados por seus respectivos TCLEs podem constituir corpus de análise. Por exemplo, imagine que em uma escola fossem aplicados 100 questionários em estudantes de 15 a 17 anos, que tivessem sido pessoalmente esclarecidos pelo pesquisador e assinado o Termo de Assentimento, e apenas 33 dentre eles obtivessem assinatura dos pais no TCLE e/ ou o devolvessem à equipe de pesquisa. Isso pode acontecer por múltiplas razões, pois raramente é possivel que a equipe de pesquisa (às vezes, composta apenas por um orientador e um orientando) se reúna pessoalmente com os representantes legais para esclarecer os propósitos e procedimentos da pesquisa. Dessa forma, recebem das mãos dos próprios filhos o documento para assinar e nem sempre eles são capazes de explicar suficientemente porque a assinatura é importante e indispensável. Assim, abre-se caminho para todo tipo de dúvidas que fazem com que os pais simplesmente não assinem ou não se lembrem de devolver o documento. Desperdício de papel é o menor problema: em uma amostra com 100 adolescentes, são 200 folhas (original recolhido pela equipe e cópia entregue ao sujeito) para registrar o Termo de Assentimento e mais 200 para o Termo de Consentimento. No total, 500 folhas, considerando uma página de questionário preenchido. Tanto empenho para aproveitar apenas $1 / 3$ das respostas coletadas. Isso mesmo! Mais da metade dos dados vão para o lixo porque os representantes legais dos sujeitos menores não devolveram o TCLE assinado. Esse é um exemplo inventado, mas qualquer semelhança com casos reais não seria mera coincidência.

De modo geral, é inviável visitar as famílias para prestar todos os esclarecimentos pessoalmente e recolher o documento assinado. Imagine que, naquele exemplo, o questionário contenha apenas três questões de múltipla escolha cujos resultados direcionariam uma seleção de amostra de entrevistados. Evidentemente, a seleção seria prejudicada e muito trabalho teria sido em vão, devido a uma coleta subaproveitada pela falta de um documento que, como já demonstrado, pode gerar mais constrangimentos do que garantia de direitos. E voltamos sempre à mesma questão: quais riscos tão graves o preenchimento de um questionário poderia causar a um adolescente que justifiquem o descarte das respostas não respaldadas por um TCLE assinado?

Reitero que a garantia de direitos - tais como liberdade, autonomia, respeito, confidencialidade, privacidade, anonimato, para citar só os principais - deve ser o primeiro compromisso de todo pesquisador responsável. Ela independe de protocolos de pesquisa, pois antecede a construção dos projetos por 
ser inerente à identidade do pesquisador. Este ensaio chama a atenção para o fato de que a forma de documentar tal garantia incorre em dois equivocos: constranger os participantes, quando esses se percebem incapazes de ler um documento ou diante de dúvidas que mal conseguem expressar, e fragilizar a coleta de dados, quando algum dos problemas supracitados intervém na coleta em si ou na interdição do uso de parte do material coletado.

\section{Reflexões finais}

Antes de encaminhar alguma conclusão, cabe um importante parênteses para informar que, durante a realização de minha pesquisa de Mestrado (2005-2008), em nenhum momento foi cogitada a necessidade de que o projeto fosse submetido a um Comitê de Ética. A única exigência feita pela orientadora, e reiterada pela Banca de Qualificação, foi o arquivamento de "termos de consentimento" assinados pelos sujeitos. Somente quando submeti um artigo a um periódico nacional foi solicitado o número do Parecer do Comitê de Ética. Informei que não havia parecer e argumentei que não entendia a necessidade, uma vez que a pesquisa já havia sido defendida e, portanto, legitimada por um programa de Pós-Graduação. Imaginava que esse fato por si só seria superior a qualquer Parecer de qualquer Comitê de Ética. A resposta da revista, no entanto, foi taxativa: sem o tal número, o artigo não seria publicado. Seguiu-se um procedimento absurdo: quase três anos após o depósito definitivo da dissertação na FEUSP, protocolei um pedido de Parecer ao seu Comitê de Ética. O pedido foi deferido e o número do Parecer divulgado no artigo (COSTA, 2011), sem que a revista questionasse a data posterior ao término da pesquisa. Apenas cumpriu-se uma formalidade para que o "rigor científico" do periódico não fosse transgredido. Mas isso foi antes de existir Pla- taforma Brasil, que não aceita, sob nenhuma hipótese, dados coletados em data anterior à do Parecer.

Só depois desse episódio, comecei a prestar atenção a esse tipo de exigência e observar que em outras áreas de conhecimento até pesquisas em nivel de Graduação exigem que o projeto seja aprovado por um Comitê de Ética. Desde que envolvam seres humanos, não importa se o material coletado consistir em respostas a um questionário ou gotas de sangue, os projetos precisam de um Parecer antes de serem executados em alguns cursos. Então, passei a me perguntar: seriam as outras áreas demasiadamente exigentes ou nós, na Educação, muito descuidados na formalização dos compromissos éticos?

O sociólogo peruano Danilo Martuccelli respondeu-me parcialmente essa questão. Ao apresentar uma de suas pesquisas em palestra na FEUSP, um estudo comparativo dos processos de individuação no Chile e na França, ele relatou que uma das diferenças percebidas no trabalho de campo estava justamente na diferenciação do "respaldo burocrático" nos dois países. Enquanto no Chile a equipe precisou se cercar de vários cuidados, entre eles a coleta de assinaturas dos sujeitos em documentos parecidos com os nossos "termos de consentimento" (sem os quais a investigação não poderia ser iniciada), na França, esse tipo de preocupação não existe. Em sua avaliação, os franceses estão tão acostumados com o trabalho dos pesquisadores que, se fossem exigir autorizações para todas as coletas de dados, as pesquisas não existiriam (Informação verbal ${ }^{12}$ ).

O que intriga nas duas situações sumariamente expostas? Se a ciência é, ao mesmo

12 Avaliação apresentada por Danilo Martucelli durante sua participação na disciplina "Pensadores clássicos e contemporâneos nas Ciências Humanas: contribuições para o campo da Educação", durante o mês de agosto de 2013. 
tempo, um tipo de conhecimento e o resultado de uma ação social que pretende se pautar em parâmetros universais, válidos e necessários em todo tempo e lugar, por que existem diferenças nos procedimentos metodológicos em função das diferenças culturais e das áreas de conhecimento? Quais seriam os limites da padronização adequados para garantir a validação e o rigor dos resultados que podem ser publicados?

Por não possuir respostas para tais questões, busquei expressar neste ensaio as inquietações de uma pesquisadora que se percebe tal como Sísifo ao ser castigado por Zeus. A lógica nuremberguiana que estrutura o Sistema CEP/CONEP trata todas as pesquisas como se fossem potenciais ameaças à integridade física, psíquica e moral dos sujeitos participantes. Nivela os procedimentos como se todos fossem invasivos e causadores de sequelas. Sujeita os projetos a rígidos tempos de execução e à obrigatoriedade de publicação de resultados, o que nem sempre é factível nas pesquisas educacionais. E em cada exigência feita pelo Sistema explicitam-se os propósitos de um Ze(us)lo que sobrecarrega os produtores de conhecimento científico com tarefas que cumprimos a contragosto, mas voltamos a cumprir, no próximo projeto, porque é assim que o Sistema determina. Em suma, de projeto em projeto, cá estamos a lidar com as formalidades exigidas para "garantir a ética" tal como Sísifo em sua eterna tarefa de levar a pedra lá para $o$ alto.

\section{Referências}

ALBUQUERQUE, Aline. Para uma ética em pesquisa fundada nos Direitos Humanos. Revista Bioética, v. 21, n. 3, p. 412-422, 2013. Disponivel em: <http:// www.scielo.br/pdf/bioet/v21n3/a05v21n3.pdf>. Acesso em: 31 ago. 2018.

AMORIM, KARLA PATRÍCIA CARDOSO. Ética em pes- quisa no sistema CEP-CONEP brasileiro: reflexões necessárias. Cien. Saúde Colet., mai. 2017. [on-line]. Disponivel em: <http://www.cienciaesaudecoletiva.com.br/artigos/etica-em-pesquisa-nosistema-cepconep-brasileiro-reflexoes-necessarias/16232?id=16232>. Acesso em: 29 set. 2018.

BOURDIEU, Pierre; CHAMBOREDON, Jean-Claude; PASSERON, Jean-Claude. Ofício de sociólogo: metodologia da pesquisa na sociologia. Tradução de Guilherme João de Freitas Teixeira. Petrópolis, RJ: Vozes, 2004.

Un acte désintéressé est-il possible? In: Raisons practiques: sur la théorie de l'action. Paris: Éditions du Seuil, 1994. p. 147-167.

Os usos sociais da ciência: por uma sociologia clínica do campo científico. São Paulo: Editora da UNESP, 2004.

BRASIL. MINISTÉRIO DA SAÚDE. CONSELHO NACIONAL DE SAÚDE (CNS) Resolução no 196, de 10 de outubro de 1996. Disponivel em: <http://bvsms.saude.gov. br/bvs/saudelegis/cns/1996/res0196_10_10_1996. html>. Acesso em: 16 ago. 2018.

Resolução no 246, de 03 de julho de 1997. Disponivel em: <http://conselho.saude.gov.br/resolucoes/reso_97.htm>. Acesso em: 16 ago. 2018.

Resolução no 466, de 12 dezembro de 2012. Disponivel em: <http://bvsms.saude.gov.br/bvs/ saudelegis/cns/2013/res0466_12_12_2012.html>. Acesso em: 16 ago. 2018.

Resolução no 510, de 07 de abril de 2016. Disponível em: <http://conselho.saude.gov.br/resolucoes/2016/reso510.pdf>. Acesso em: 16 ago. 2018.

Carta Circular no 110-SEI/2017-CONEP/

SECNS/MS. Disponivel em: <http://www.ufjf.br/ comitedeetica/2017/12/18/carta-circular-no110-sei2017-conepsecnsms/>. Acesso em: 16 ago. 2018.

BRASIL. MINISTÉRIO DA CIÊNCIA E TECNOLOGIA. CONSELHO NACIONAL DE DESENVOLVIMENTO CIENTÍFICO E TECNOLÓGICO (CNPq). Objetivos do Programa PIBIC. Disponível em: <http://www.cnpq.br/web/ guest/pibic>. Acesso em: 26 set. 2018. 
COSTA, Patrícia Claudia. Sem medo de ser falante: conquistas da oralidade por educandas idosas do MOVA-Guarulhos. 2008. 197 f. Dissertação (Mestrado em Educação) - Faculdade de Educação, Universidade de São Paulo, São Paulo, 2008.

. O que se aprende além das letras: um estudo sobre a alfabetização de pessoas idosas. Revista Brasileira de Geriatria e Gerontologia, Rio de Janeiro, v. 14, n. 4, p. 721-730, 2011.

Auto-hermenêutica em pesquisas auto-

biográficas. Revista Brasileira de Pesquisa (Auto)

Biográfica, Salvador, v.1, p. 75-88, 2016.

Das escol(h)as possiveis à carreira do ma-

gistério superior federal: condicionantes sociais das trajetórias de docentes oriundos de famílias pobres e sem tradição de longevidade escolar. 2017. 301 f. Tese (Doutorado em Educação) - Faculdade de Educação, Universidade de São Paulo, São Paulo, 2017.
FREIRE, Paulo. Pedagogia da autonomia: saberes necessários à prática educativa. 42. ed. São Paulo: Paz e Terra, 2010.

JOSSO, Marie-Christine. Experiências de vida e formação. São Paulo: Cortez, 2004.

LIMA, Ana; CATELLI JUNIOR, Roberto. INAF Brasil 2018: Resultados Preliminares. Disponivel em: <http:// acaoeducativa.org.br/wp-content/uploads/2018/08/ Inaf2018_Relatório-Resultados-Preliminares_v08Ag02018.pdf> . Acesso em: 31 ago. 2018.

MOTA, Fernanda R. N.; ALBUQUERQUE, Danielle B.; OLIVEIRA, Edmara T.; ARAÚJO, Natálya R.; BESSA, Maria E. P.; SILVA, Maria J. Elaboração de instrumento de coleta de dados para pesquisa com idosos. Revista Brasileira de Enfermagem, Brasília, v. 64, n. 2, p. 389-392, mar./abr. 2011.

Recebido em: 09/11/2018 Aprovado em: 18/04/2019

Patrícia Claudia Costa é Mestra e Doutora em Educação pela USP. Docente da área de Fundamentos da Educação na Universidade Federal de Viçosa Campus Florestal. e-mail: patricia.claudia@ufv.br

Rodovia LMG 818, km 06. Campus da UFV. Florestal, MG. CEP: 35690-000

(31) $3536-3358$ 